\title{
The kinetic behavior of antioxidant activity and the stability of aqueous and organic polyphenol extracts from navel orange peel
}

\author{
Limei YU1,2,3,4, Yingxian WU1 (D), Dongjie LIU ${ }^{1}$, Zhili SHENG ${ }^{5}$, Junmei LIU ${ }^{5}$, Haiguang CHEN ${ }^{1,2,4}$, Weihua FENG ${ }^{1,4 *}$
}

\begin{abstract}
The kinetic behavior of the antioxidant activity of aqueous/organic polyphenol extracts from navel orange peel was evaluated using DPPH and FRAP assays to assess their capacity to scavenge DPPH and ferric reducing antioxidant power. The stability of polyphenol extracts, including the influencing factors of temperature, $\mathrm{pH}$, light, and the correlation of total phenolic content and antioxidant activity were also investigated. The kinetic reaction results showed that the antioxidant activity i.e. DPPH radical scavenging capacity and ferric reducing antioxidant power depended on concentration and reaction time. Its stability in aqueous phase and organic phase was influenced by temperature, $\mathrm{pH}$ and light in varying degrees. $50{ }^{\circ} \mathrm{C}$ was a key temperature point above which the total polyphenol content and antioxidant ability decreased remarkably. The phenolic compounds were not stable at $\mathrm{pH} 7$, but showed a strongest DPPH radical scavenging capacity in both aqueous and organic phases. Acidic conditions seemed to be better for maintaining antioxidant ability of extracts from navel orange peel than alkaline conditions in aqueous and organic phases. Avoiding light kept the extracted phenolic compounds stable. There is a significant correlation between total phenolic content and antioxidant activity. These results provide some basic understanding of extracts from navel orange peel and promote the application of the extracted polyphenol from navel orange peel as antioxidants.
\end{abstract}

Keywords: navel orange peel; polyphenol; antioxidant activity; stability.

Practical Application: Queous/organic polyphenol extracted from navel orange peel was investigated, for the kinetic behavior of the antioxidant activity, physicochemical stability and the correlation of total phenolic content and antioxidant activity. This study provides a theoretical basis for the application of navel orange peel polyphenols as antioxidants.

\section{Introduction}

There are more recent evidences that free radicals induce oxidative damage, which has been implicated in ageing and in several human pathologies and other diseases (Gliszczyńska-Świgł, 2006). Several studies indicate that adequate intake of fruits and vegetables prevent these chronic diseases caused by oxidative stress (Zhang \& Tsao, 2016; Tabart et al., 2009). Numerous studies have shown that plant polyphenol have good effects on anti-mutagenesis, antiaging, anti-cancer, anti-inflammatory, anti-diabetes, weight loss and neuroprotection (Braicu et al., 2013; Hano, 2020; Williams \& Spencer, 2012; Zaveri, 2006), and have certain therapeutic or preventive effects on some diseases that seriously harm human health, such as hypertension, heart disease, cancer and so on (Hertog et al.,1993; DuPont et al., 2002). These protective effects have been given credit for the antioxidant substances, such as polyphenolic compounds, carotenoids, vitamins $\mathrm{C}$ and $\mathrm{E}$. Antioxidants have capability against scavenging reactive oxygen and nitrogen species and prevent oxidative damage to crucial biological macromolecules, such as DNA, lipids, and protein (Singh et al., 2018; Szeto et al., 2004). Natural antioxidants have been found to be safer than many synthetic ones and can provide additional nutritional value (Ajila et al., 2007). This has led to increasing development of natural antioxidants, especially from fruits and vegetables.
Citrus fruits are the most abundant fruits grown throughout the world containing valuable antioxidant phytochemicals (Hou et al., 2019; Satari \& Karimi, 2018). Navel orange is a type of citrus which is among the most popular orange varieties. It has good economic value and is widely cultivated in countries such as China, Brazil, the United States, and Spain. By the end of 2017, Guangzhou has been the largest production area of navel oranges in China with the total planting areas of navel orange 103.2 thousand hectares, and the annual output of around 1.24 million tons (Zhang et al., 2018). Navel orange is a commonly consumed product because of its high nutritional value and desirable sensorial characteristics, which are attributed to a large supply of antioxidant compounds mainly vitamin $\mathrm{C}$ and polyphenols as well as dietary fiber content (Nicolle et al., 2004; Serafini et al., 2002). With the consumption of orange pulp, huge amounts of orange peel are wasted, which account for about $30 \%$ of the weight of the whole fruits (Rezzadori et al., 2012). Traditionally, orange peel is commonly used as a substrate to produce animal feed, organic fertilizer, and biofuel (Santos et al., 2010).

The navel orange peel residue is a source of phenolic compounds, including antioxidant active substances such as 
phenolic acids and flavonoids (Rafiq et al., 2018). It is worth noting that the polyphenolic compounds from orange peel have aroused great research interests worldwide, due to their structure and biodiversity that present antioxidant, antibacterial, enzyme inhibition, anti-inflammatory, and antitumour activity (Shirisha et al., 2019; Smeriglio et al., 2019; Mandalari et al., 2007; Bobo-García et al., 2015; Klangpetch et al., 2016).The application of natural antioxidants as health-promotion supplements or as a food preservative has currently gained much attention.

The antioxidant activity is normally evaluated at a fixed timepoint, which can hardly avoid instrumental errors. Besides, this evaluation method is used without considering if the reaction is extensively completed. Therefore, some researchers have proposed a kinetic approach in determining the antioxidant activity of citrus juices, sesame extracts (Suja et al., 2004) and red wines (Magalhães et al., 2012). The polyphenols with hydroxyl groups, especially ortho phenolic hydroxyl groups, are active and can be easily affected by enzymes, oxygen, light, moisture, and other factors. The stability of phenolic compounds needs further investigation to assess their antioxidant ability under various temperatures and $\mathrm{pH}$ conditions.

At present, there were many studies mainly focused on the extraction of active ingredients from navel orange peel (Guo et al., 2012; Yang et al., 2009; Lux et al., 2019). However, limited data are available on the antioxidant activity kinetic behavior of different phase phenolic extracts from navel orange peel. In the present study, the reaction kinetics of aqueous/organic phase polyphenol extracts were clarified for the antioxidant properties by DPPH radical scavenging assays and ferric reducing-antioxidant power (FRAP) assay. Meanwhile, the stability of aqueous/organic phases polyphenol extract, and the correlation between the content changes of polyphenol and antioxidant activity under the different factors were also investigated. They could contribute to the value-added utilization of this orange peel in the food, cosmetic, and pharmaceutical industries.

\section{Materials and methods}

\subsection{Chemicals and reagents}

Gallic acid, Folin phenol reagent, 2,2'-diphenyl-1-picrylhydrazl (DPPH), 2,4, 6-Tis-2,4,6-tripyridyl-2-triazine (TPTZ) were purchased from Sigma-Aldrich GmbH (Sternheim, Germany), $\mathrm{Na}_{2} \mathrm{CO}_{3}$, ethyl alcohol, Butylated hydroxytoluene (BHT), sodium acetate, acetic acid, methanol, concentrated hydrochloric acid, acetone, ethyl acetate, n-hexane were obtained from Yima Chemical Reagent Factory (Guangzhou, China). All solvents were analytical grade.

\subsection{Plant material}

Navel oranges were purchased from Carrefour Supermarket (Guangzhou, China). Navel orange peels were peeled off from the fresh fruits by hand, and dried at $50{ }^{\circ} \mathrm{C}$ in electric constant temperature drying oven (Flyde, Guangzhou, China) until constant weight was obtained, then crushed by using a high speed pulverizer (Ruian, Yonglu Pharmaceutiical Co.,LTD, Zhejiang,
China). The powder was passed through a mesh 40 and stored at room temperature after sealing.

\subsection{Preparation of phenolic extracts}

The polyphenols extraction was performed on samples according to Yan et al. (2012). $0.5 \mathrm{~g}$ of sample that has been sampled by the quartile method was mixed with $10 \mathrm{~mL}$ of ethanol/ water $(50: 50 \mathrm{v} / \mathrm{v})$ for $2 \mathrm{~h}$ at $60^{\circ} \mathrm{C}$ in the dark. The mixture was then centrifuged $\left(13,000 \mathrm{~g}, 25^{\circ} \mathrm{C}\right)$ for $20 \mathrm{~min}$. The supernatant obtained was concentrated under vacuum at $40^{\circ} \mathrm{C}$ by using a rotary evaporator (Gongyi Yuhua Instrumeny Co.,LTD, Henan, China), and defatted with hexane (samples/solvent, 1:1, v/v) for six times, then extracted with ethyl acetate/anhydrous ether (samples/solvent, 1:1, v/v) for six times. Then hexane phase/ethyl acetate phase /anhydrous ether phase was evaporated respectively at $30^{\circ} \mathrm{C}$ by rotary evaporation until dried. The rest of aqueous phase was freeze-dried at $-46{ }^{\circ} \mathrm{C}$ in a vacuum freeze dryer (Boyikang Lab Instrument Co.,LTD, Beijing, China). The dried hexane phase/ethyl acetate phase /anhydrous ether phase was adjusted to a final volume of $5 \mathrm{~mL}$ with ethanol solution $(50 \%$, $\mathrm{v} / \mathrm{v}$ ) to determine the polyphenol content respectively.

\subsection{Total phenolic content (TPC)}

Total phenol content (TPC) in each extract was determined using the FC method described by McDonald et al. (2001), with slight modifications. The calibration curve was established using gallic acid $(0 \sim 45 \mu \mathrm{g} / \mathrm{mL})$. Phenol extract $(0.5 \mathrm{~mL})$ was transferred into $5 \mathrm{~mL}$ volumetric flasks, added distilled water $(3 \mathrm{~mL})$ and $\mathrm{FC}$ reagent $(0.25 \mathrm{~mL})$, and mixed thoroughly for $3 \mathrm{~min} .20 \% \mathrm{Na}_{2} \mathrm{CO}_{3}$ solution $(0.75 \mathrm{~mL})$ was added to the mixture and the mixture was diluted to $5.0 \mathrm{~mL}$ with distilled water. The mixture was incubated in water bath at $75{ }^{\circ} \mathrm{C}$ for $10 \mathrm{~min}$ and rapidly cooled in ice bath, then centrifuged at $4000 \mathrm{r} / \mathrm{min}$ for $10 \mathrm{~min}$. The absorbance of the mixture was measured at $760 \mathrm{~nm}$ using a spectrophotometer (BECKMAN COUCTER, USA). The blank consisted of all reagents and solvents without samples. The total phenolic content was calculated from the calibration curve, and the results were expressed as $\mathrm{mg}$ of gallic acid equivalent per g dry weight (mg GAE/g). Determination of TPC was conducted in a duplicate.

\subsection{DPPH radical scavenging assay}

The DPPH free radical scavenging rate of extracts were determined by the method of Calliste et al. (2005) with minor modifications. Briefly, $0.2 \mathrm{~mL}$ of sample was added into $4 \mathrm{~mL}$ DPPH ethanol solution $(0.1 \mathrm{mM})$. The absorbance was measured at $517 \mathrm{~nm}$ using a UV VIS spectrophotometer every $10 \mathrm{~min}$ from $0 \mathrm{~min}$ to $60 \mathrm{~min}$. The percentage inhibition of radicals was calculated using the following formula (Equation 1):

\%inhibition $=\left(A_{\text {control }}-A_{\text {sample }}\right) \times 100 / A_{\text {control }}$

where $\mathrm{A}_{\text {control }}$ is the absorbance of DPPH solution without extract and $\mathrm{A}_{\text {sample }}$ is the absorbance of sample with DPPH solution. The DPPH radical scavenging capacity is inhibition or $\mathrm{EC}_{50}$ 
value. The half-maximal inhibitory concentration $\left(\mathrm{EC}_{50}\right)$ was reported as the amount of antioxidant required to decrease the initial DPPH concentration by 50\% (Do et al., 2014). A lower absorbance or $\mathrm{EC}_{50}$ value indicates a stronger capability to scavenge DPPH radicals. All tests were performed at least in triplicate, and graphs were plotted using the average of three determinations.

\subsection{Ferric reducing-antioxidant Power (FRAP) assay}

The ferric reducing antioxidant power (FRAP) assay was conducted according to the procedures described by Benzie \& Strain (1996) with some modifications. The FRAP reagent contained $2.5 \mathrm{~mL}$ of $10 \mathrm{mM}$ TPTZ solution in $40 \mathrm{mM} \mathrm{HCl}$ plus $2.5 \mathrm{~mL}$ of $20 \mathrm{mM} \mathrm{FeCl}_{3} \cdot 6 \mathrm{H}_{2} \mathrm{O}$ and $25 \mathrm{~mL}$ of $0.3 \mathrm{M}$ acetate buffer, $\mathrm{pH} 3.6$, and was prepared freshly and warmed at $37^{\circ} \mathrm{C}$ prior to use. The FRAP reagent $(3600 \mu \mathrm{L})$, prepared and warmed to $37^{\circ} \mathrm{C}$, was mixed with distilled water $(360 \mu \mathrm{L})$ and Polyphenol extract $(120 \mu \mathrm{L})$ of navel orange peel. The absorbance was measured at $593 \mathrm{~nm}$ every $10 \mathrm{~min}$ from $0 \mathrm{~min}$ to $60 \mathrm{~min}$ against a blank without samples ( $120 \mu \mathrm{L}$ distilled water instead). A standard curve was prepared using different concentrations of $\mathrm{FeSO}_{4} .7 \mathrm{H}_{2} \mathrm{O}(0 \mathrm{mM} 、 0.2 \mathrm{mM} 、 0.4 \mathrm{mM} 、 0.6 \mathrm{mM}$ 、 $0.8 \mathrm{mM} 、 1.0 \mathrm{mM}$ ). The evaluation index of ferric reducing antioxidant power is absorbance or $\mathrm{EC}_{1}$ value (the dose of an antioxidant $\left(\mathrm{mmol} \mathrm{Fe}^{2+} / \mathrm{g}\right.$ ) has the same antioxidant capacity as $1 \mathrm{mM} \mathrm{FeSO}_{4} .7 \mathrm{H}_{2} \mathrm{O}$ ). The FRAP is stronger with the higher of absorbance or $\mathrm{EC}_{1}$ value. Increased absorbance or $\mathrm{EC}_{1}$ value of the reaction indicated increased ferric reducing-antioxidant Power.

\subsection{Investigation of the stability of polyphenol extract}

\section{Effect of temperature on the total phenolic content and antioxidant activity}

The aqueous/organic phase polyphenol extract were added to centrifuge tubes and stored in warm bath at $30^{\circ} \mathrm{C}, 40{ }^{\circ} \mathrm{C}$, $50{ }^{\circ} \mathrm{C}, 60^{\circ} \mathrm{C}$ and $70{ }^{\circ} \mathrm{C}$ for $30 \mathrm{~min}$. The TPC, $\mathrm{EC}_{50}$ and $\mathrm{EC}_{1}$ of each sample was measured respectively.

\section{Effect of $\mathrm{pH}$ on the total phenolic content and antioxidant activity}

Buffer solutions used were disodium hydrogen phosphate and citric acid buffer, $\mathrm{pH}$ 3.0, 4.0 and 5.0; disodium hydrogen phosphate buffer, $\mathrm{pH}$ 6.0, 7.0 and 8.0; Tris- $\mathrm{HCl}$ buffer, $\mathrm{pH}$ 9.0 and 10.0. The aqueous/organic phase polyphenol extract were mixed with equivalent buffer respectively in centrifuge tubes and incubated at room temperature for $1 \mathrm{~h}$. The TPC, $\mathrm{EC}_{50}$ and $\mathrm{EC}_{1}$ of each sample was measured respectively.

\section{Effect of light on the total phenolic content and antioxidant activity}

The aqueous/organic phase polyphenol extract were added to centrifuge tubes and irradiated for $0,12,24,48,72$ and $96 \mathrm{~h}$ under simulated natural light ( $25 \mathrm{~W}$ incandescent lamp). The TPC, $\mathrm{EC}_{50}$ and $\mathrm{EC}_{1}$ of each sample was measured respectively.

\subsection{Data statistics and analysis}

All the analyses were carried out in triplicates. The obtained results were presented as mean (c) \pm (standard deviation (SD). All data were disposed using SPSS software, and analysis of variance (ANOVA) and Duncan's multiple range method were used to compare any significant differences. The correlation of the variables was analysed by Pearson correlation test. Differences were considered significant at $p<0.05$ or very significant at $p<0.01$.

\section{Results and discussion}

\subsection{DPPH radical-scavenging activities}

The DPPH radical is a stable radical with maximum absorption at $517 \mathrm{~nm}$ that can readily undergo reduction by an antioxidant ( $\mathrm{Lu} \&$ Foo, 2000). DPPH is usually used as a reagent to evaluate free radical scavenging activity of antioxidants (Tohma \& Gulçin, 2010). As shown in Figure 1, the DPPH radical scavenging capacity increased with increasing phenolic content and reaction time. The results indicated that the aqueous/organic phases polyphenol extract both have strong and lasting DPPH radical-scavenging activities at the concentration above $100 \mathrm{mg}$ GAE/g DW. The absorption value decreased rapidly in the first 10 mins, then reached a plateau after 50 mins. The research group from Slovenia (Terpinc et al., 2009) reported a similar conclusion on the polyphenol antioxidant activity indicating that phenolic compounds exhibited a concentration-dependent increase of scavenging rate. It is consistent with our results that the DPPH radical scavenging capacity of aqueous /organic phase polyphenol extract depends on concentration and reaction time, while our results showed a higher scavenging capacity at a similar concentration. Besides, both aqueous phase and organic phase showed a similar trend of DPPH radical-scavenging activities,no significant difference.

\subsection{Ferric Reducing Antioxidant Power (FRAP)}

The ferric reducing antioxidant power of aqueous/organic phase polyphenol extracts were shown in Figure 2. It suggested a similar conclusion with DPPH radical scavenging capacity that aqueous/organic phase polyphenol extracts showed a concentration and time dependent increase in the ferric reducing antioxidant power. The color reaction initiated rapidly in $10 \mathrm{mins}$, followed by a time-dependent increase during the first $50 \mathrm{~min}$, and a plateau afterwards (Figure $2 \mathrm{AB}$ ). These values suggested that ferric reducing antioxidant power of aqueous/organic phases polyphenol extract were strong. The results are consistent with previous studies, which demonstrated a strong positive correlation between the total phenolic content and the antioxidant capacity of fruits. (Wang \& Lin, 2000; Dai et al., 2007; Bagetti et al., 2011)

\subsection{The effect of temperature on polyphenol content and its antioxidant activity}

The total phenolic content from navel orange peel extracts in aqueous phases decreased as the temperature of warm bath increased between $30^{\circ} \mathrm{C} \sim 70^{\circ} \mathrm{C}$ (Figure $3 \mathrm{~A}$ ), while no significant loss of total phenolic content in organic phase were observed in the 

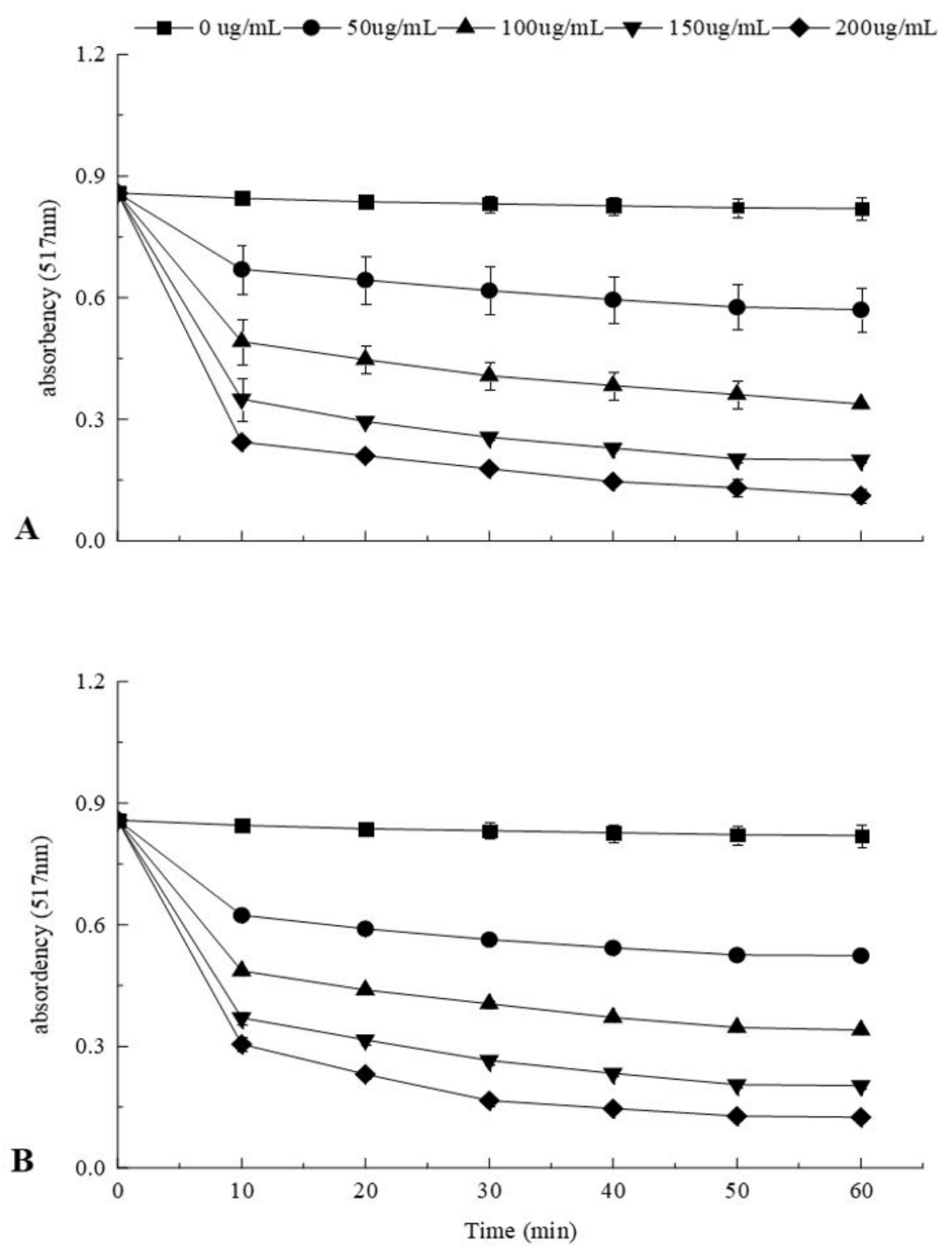

Figure 1. Reaction kinetics of phenolic extract in aqueous phase (A) or organic phase (B) with DPPH assay.

same temperature range from $30^{\circ} \mathrm{C}$ to $60^{\circ} \mathrm{C}$. Significant loss (around $10 \%$ of total phenolic content) only occurred above $70^{\circ} \mathrm{C}$, which suggested that total phenolic content in organic phase are relatively stable under high temperature conditions. By contrast, phenolic content in aqueous phase was not as stable as those in organic phase. There was a $16 \%$ reduction of total phenolic compounds in aqueous phase at $70^{\circ} \mathrm{C}$. It has been reported that total phenolic content and free radical scavenging activities decreased with increasing extraction temperatures. (Akowuah et al., 2009). It is worth to note that total phenolic content was twice more exacted from water than that from organic solvent at both low and high temperature.

Temperature exerted different effects on the DPPH radical scavenging capacity of polyphenol extracts in Figure 3B. As shown in Figure $3 \mathrm{~B}$, the low $\mathrm{EC}_{50}$ was only observed below $50{ }^{\circ} \mathrm{C}$ and there was no significant difference between aqueous and organic phase, indicating that the strong free radical-scavenging capacity of the polyphenol extract can be maintained up to $50^{\circ} \mathrm{C}$. However, $\mathrm{EC}_{50}$ remarkably increased above $50{ }^{\circ} \mathrm{C}$ with a $48 \%$ increase in aqueous phase and $100 \%$ increase in organic phase (Figure 3B). These changes in free radical-scavenging capacity were consistent with changes in total phenolic content.

As shown in Figure 3C, EC showed slightly increase in organic phase and decrease in aqueous phase, suggesting that temperature had positive effects on the ferric reducing antioxidant power of polyphenol extract in organic phase, but caused a 13.5\% reduction in aqueous phase at $70^{\circ} \mathrm{C}$.

All the results suggested that $50^{\circ} \mathrm{C}$ was a key temperature to maintain the high antioxidant activity of polyphenol extracts, 

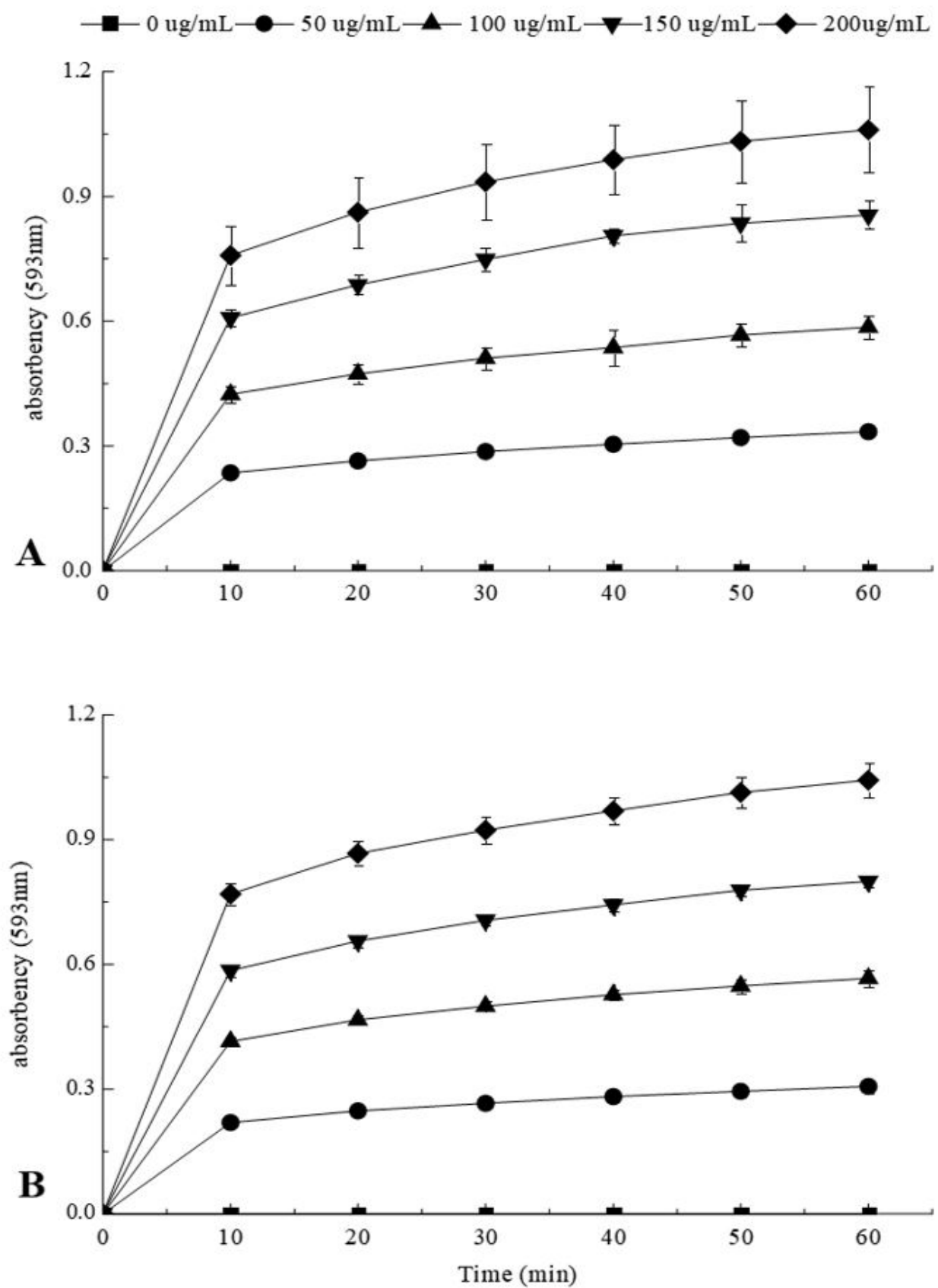

Figure 2. Reaction kinetics of different concentrations of navel orange peel phenolic extract in aqueous phase (A) or organic phase (B) with FRAP assay.

which could be due to the combined effect of nonenzymatic reaction and anthocyanin stability (Reyes \& Cisneros-Zevallos, 2007). Temperature significantly affected the stability of total phenolic content and its antioxidant activity in aqueous phases compared with that in organic phase. The differences in temperature sensitivity of polyphenol extract between aqueous phase and organic phase, maybe due to the structures of phenolic compounds, i.e. mainly oligomer and monomer in organic phase and multimer in aqueous phase.. The antioxidant ability of navel orange peel extracts was not determined by total polyphenol content but the specific structures of phenolic compounds that related to their stability at high temperature.

\subsection{The effect of $p H$ on polyphenol content and its antioxidant activity}

The influence of various $\mathrm{pH}$ on the content and its antioxidant activity of aqueous/organic phases polyphenol extract were investigated. As it was shown in Figure 4A, the aqueous phase polyphenol content was significantly higher at $\mathrm{pH} 3.0 \sim 7.0$ than 

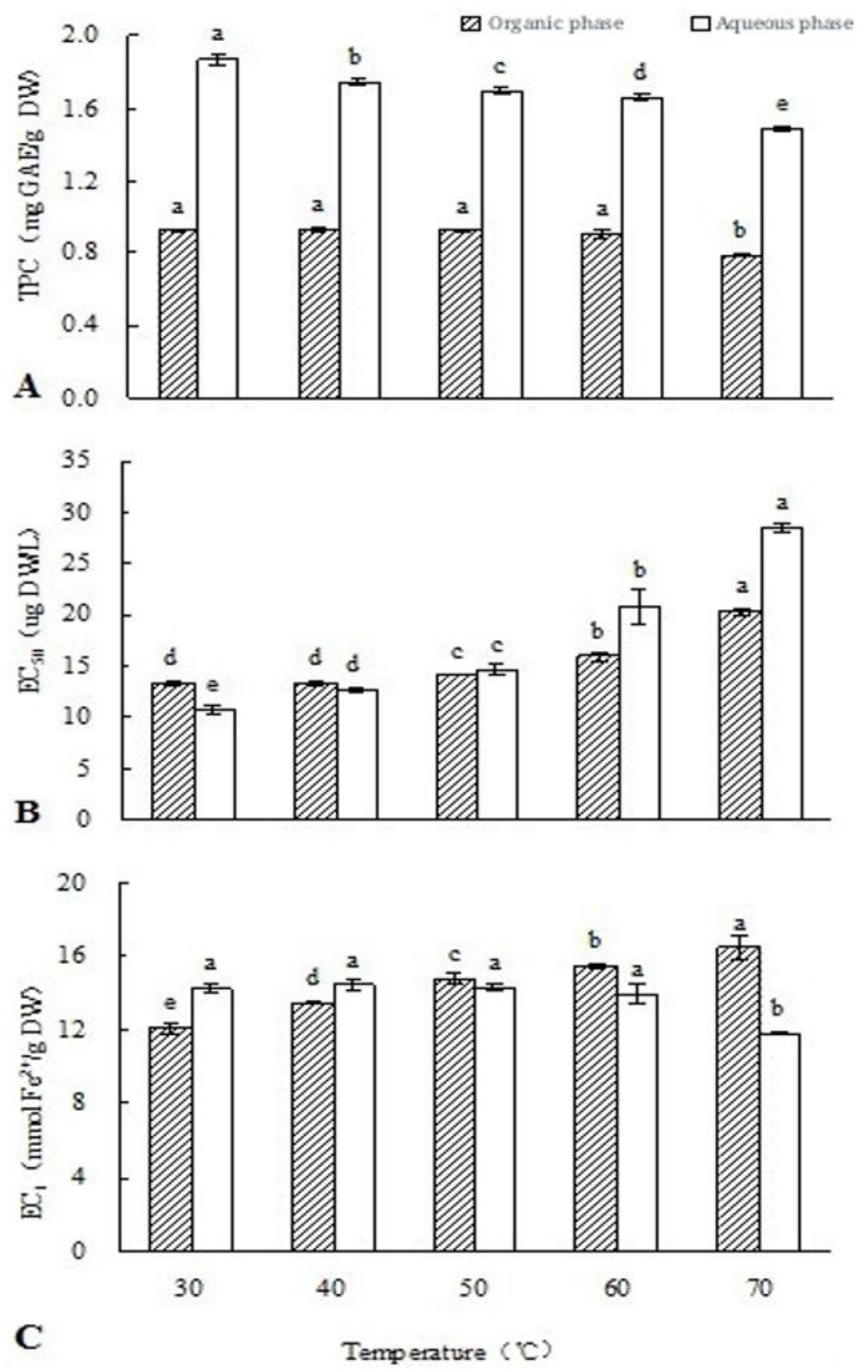

Figure 3. Effects of temperature on TPC and the antioxidant activity of navel orange peel phenolic extract. In each column, the data having different letters are statistically different $(p<0.05)$.

that at $\mathrm{pH} 8.0 \sim 10.0(p<0.05)$. The aqueous phase polyphenol was relatively stable at $\mathrm{pH} 3.0 \sim 7.0$. It is interesting to note that the content of total phenolics in organic phase was lowest at neutral condition ( $\mathrm{pH} 7$ ), while polyphenols in organic phase were stable in acidic and alkaline conditions (Figure 4A). This result is consistent with $\mathrm{EC}_{50}$ (Figure $4 \mathrm{~B}$ ) and $\mathrm{EC}_{1}$ (Figure $4 \mathrm{C}$ ).

Figure $4 \mathrm{~B}$ shows that DPPH radical scavenging capacity of organic phases polyphenol extract at different $\mathrm{pH}$ can be ranked in the order $\mathrm{pH} 7.0>\mathrm{pH} 6.0>\mathrm{pH} 5.0>\mathrm{pH} 10.0>\mathrm{pH} 3.0>\mathrm{pH}$ $8.0>\mathrm{pH} 9.0>\mathrm{pH}$ 4.0. In aqueous phases, it can be ranked in the order $\mathrm{pH} 7.0>\mathrm{pH} 4.0>\mathrm{pH} 5.0>\mathrm{pH} 3.0>\mathrm{pH} 9.0>\mathrm{pH} 8.0>\mathrm{pH}$ $6.0>\mathrm{pH}$ 10.0. The results neutral condition $(\mathrm{pH} 7)$ facilitates to scavenge DPPH radicals and the DPPH radical scavenging capacity was stronger in acidic conditions than that in alkaline conditions in both organic and aqueous phases.

As shown in Figure 4C, the ferric reducing antioxidant power of aqueous phase polyphenol extract was much higher at $\mathrm{pH} 8.0 \sim 10.0(p<0.05)$ than that at $\mathrm{pH} 3.0 \sim 7.0$, and was lowest in neutral conditions. However, it was significantly higher in organic phase at $\mathrm{pH} 7.0(p<0.05)$ than at other $\mathrm{pH}$ values, and 

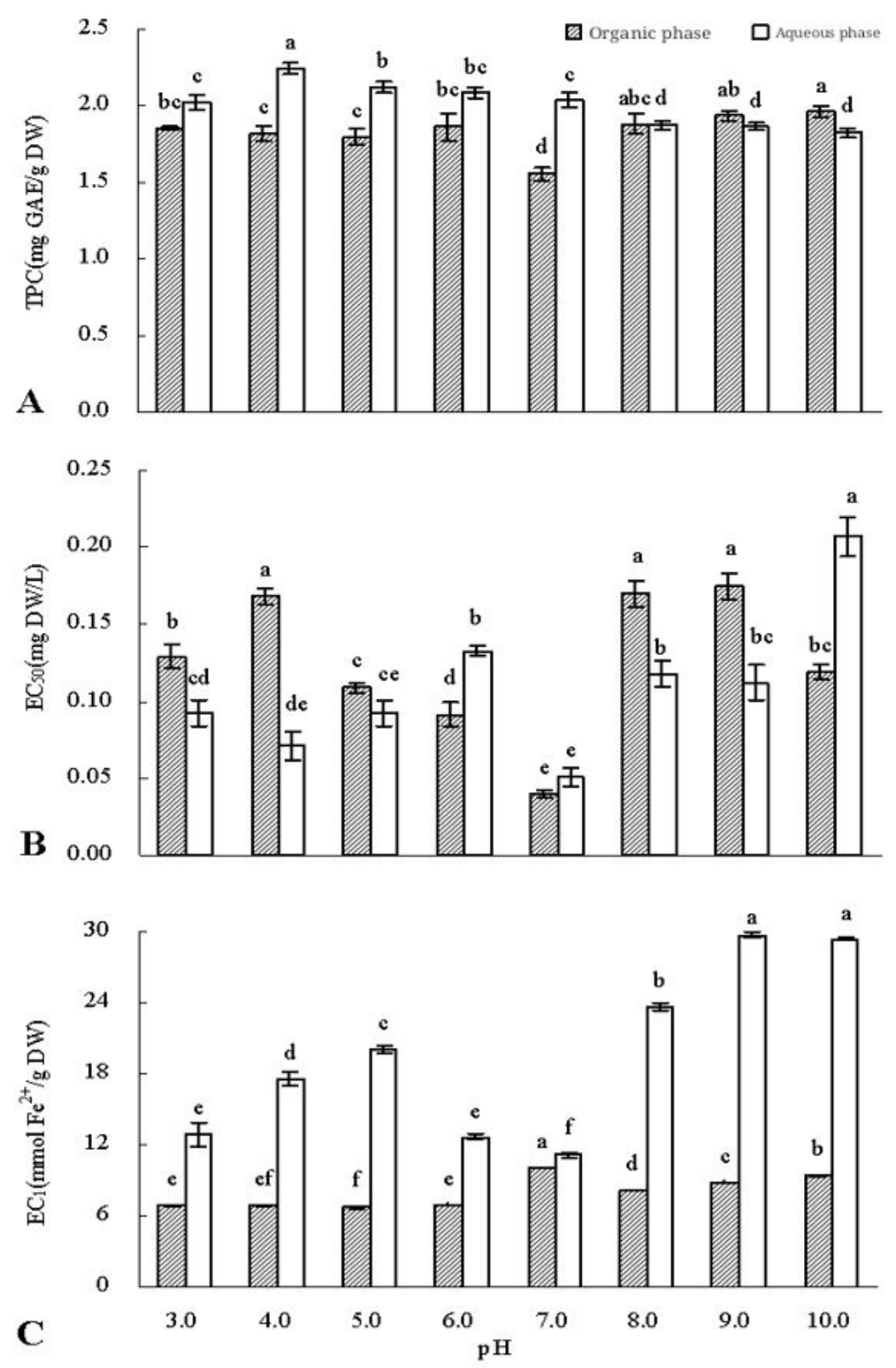

Figure 4. Effects of $\mathrm{pH}$ on TPC and the antioxidant activity of navel orange peel phenolic extract.In each column, the data having different letters are statistically different $(p<0.05)$.

it was higher in alkaline conditions than in acid conditions. $\mathrm{pH}$ variation in acid conditions. On the polyphenol extracts resulted in a lower amount of the functional substances. These results demonstrate that various $\mathrm{pH}$ significantly influenced the content and its antioxidant activity of aqueous/organic phases polyphenol extract, which could be due to the polyphenol stability. It was reported that the $\mathrm{pH}$ significantly influenced polyphenol content and the total antioxidant ability (Ruenroengklin et al., 2008; Yuan,2014).

Friedman \& Jürgens (2000) reported that the stability of phenolic substances strongly depends not only on $\mathrm{pH}$ but also on the phenolic substance structure. Each radical group in the phenolic compounds reacts in different ways with the media $\mathrm{pH}$ variation, which can be affected by electron-donating or withdrawing and sterically hindering of substituent on the aromatic ring (Ganapathi et al., 2001).

Harbourne et al. (2009) studied the effect of $\mathrm{pH}$ on the extraction of total phenols from meadow sweet (Filipendula ulmaria L.) using water as solvent and concluded that when increasing the $\mathrm{pH}$ from 3.9 to 6.4 , total phenols content was $33 \%$ higher. On the other hand, Yoshida et al. (1999) studied the efficiency of phenolic compounds extraction from green 
tea and observed a decrease in the extraction efficiency when $\mathrm{pH}$ was increased, reaching a $30 \%$ less extraction at $\mathrm{pH} 6.0$ and $15 \%$ at $\mathrm{pH} 7.6$.

\subsection{The effect of light on polyphenol content and its antioxidant activity}

The polyphenol content of aqueous and organic phases decreased significantly with increasing illumination time in a similar pattern as observed in Figure 5A. In general, the polyphenol content was higher in aqueous phase than that in organic phase.

As shown in Figure 5B, the influence of DPPH radical scavenging capacity was higher significant. All types of illumination time significantly $(p<0.05)$ influenced the DPPH radical scavenging capacity of aqueous phase polyphenol. However, there was no significant difference on DPPH radical scavenging capacity of organic phase polyphenol in $0 \sim 12 \mathrm{~h}$ range. It decreased remarkably between $12 \mathrm{~h}$ and $96 \mathrm{~h}(p<0.05)$.
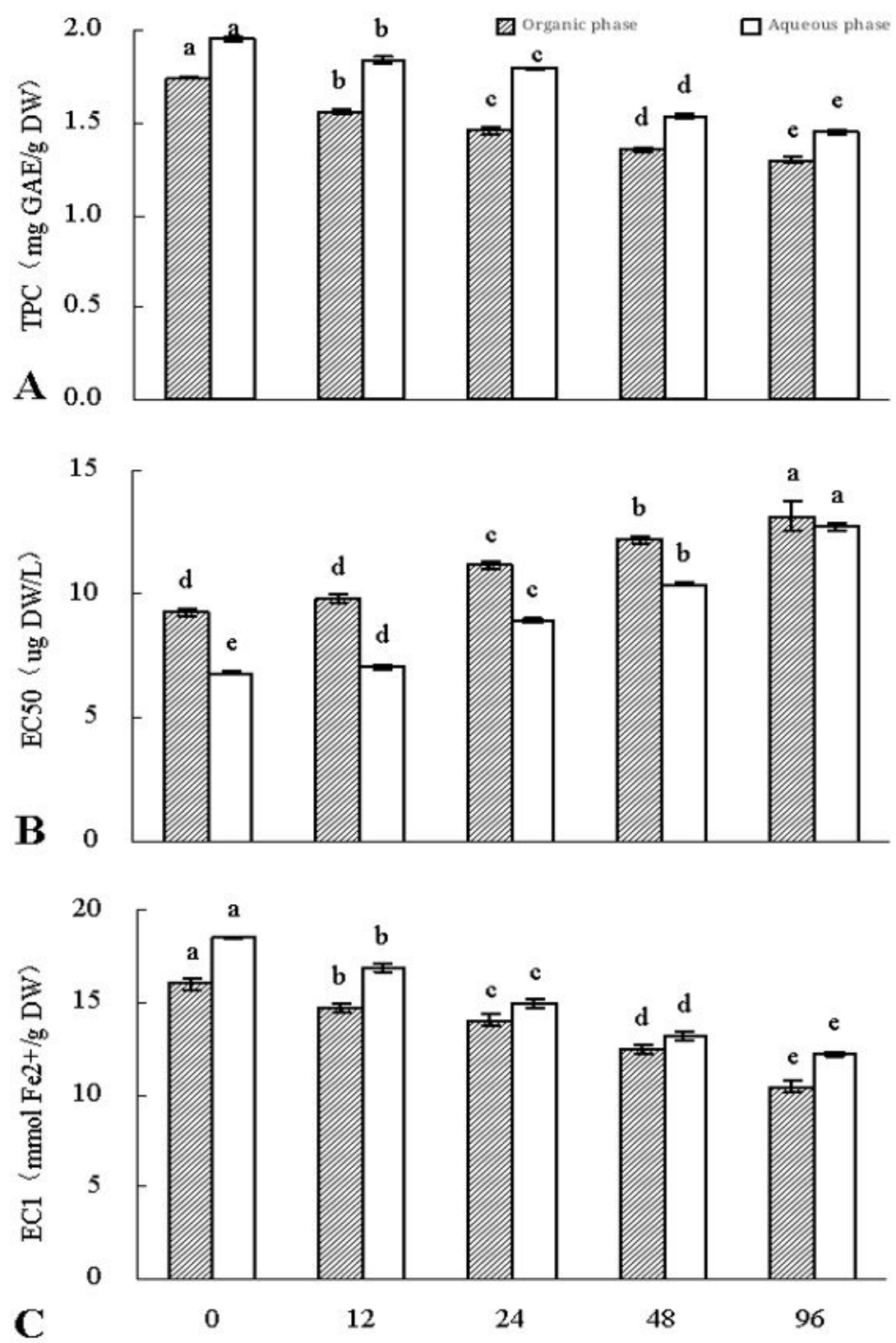

Illumination time $(h)$

Figure 5. Effects of light on TPC and the antioxidant activity of navel orange peel phenolic extract.In each column, the data having different letters are statistically different $(p<0.05)$. 
Table 1. Correlations between TPC and antioxidant activity of phenolic in navel orange peel at different factors.

\begin{tabular}{|c|c|c|c|}
\hline Factors & Samples & Correlation coefficients against $\mathrm{EC}_{50}$ & Correlation coefficients against EC \\
\hline \multirow[t]{2}{*}{ Temperature } & aqueous phase & $-0.939^{\star *}$ & $0.808^{* *}$ \\
\hline & organic phase & $-0.926^{* *}$ & $-0.686^{* *}$ \\
\hline \multirow[t]{2}{*}{$\mathrm{pH}$} & aqueous phase & $-0.619^{* *}$ & $-0.663^{\star *}$ \\
\hline & organic phase & $0.669^{* *}$ & -0.226 \\
\hline \multirow[t]{2}{*}{ Light } & aqueous phase & $-0.954^{\star *}$ & $0.969^{* *}$ \\
\hline & organic phase & $-0.951^{\star *}$ & $0.940^{* *}$ \\
\hline
\end{tabular}

All results were expressed as mean $\pm \mathrm{SD}$ of three parallel measurements. ${ }^{* *}$ indicated very significant correlations at $p<0.01$ (two-tailed)

Effect of light on ferric reducing antioxidant power of aqueous/organic phases polyphenol was shown in Figure 5C. The ferric reducing antioxidant power of polyphenol extract in aqueous/organic phases was changed observably in the range of $0 \sim 96 \mathrm{~h}$, and it decreased significantly $(p<0.05)$ as the illumination time increased. It demonstrated aqueous/ organic phases polyphenols content and its antioxidant activity was sensitive to light. Some investigations had shown that the polyphenol content and its antioxidant activity was significantly affected on the light (Yin et al., 2015; Yuan, 2014), which was in accordance with our results.

\subsection{The correlation between TPC and antioxidant activity under different conditions}

There was a correlation between the polyphenol content and its antioxidant activity under different conditions as shown in Table 1.

In terms of temperature, aqueous phase polyphenol content was significantly negatively correlated with its corresponding $\mathrm{EC}_{50}$ and positively correlated with its corresponding $\mathrm{EC}_{1}(p<0.01)$. Moreover, there was a significantly negative correlation between organic phase polyphenol content and its corresponding $\mathrm{EC}_{50}$ and $\mathrm{EC}_{1}(p<0.01)$. The results suggested that the effect of temperature on antioxidant activity of aqueous and organic phase polyphenols was significant due to polyphenol sensitive to temperature. Temperature had a significant effect on polyphenol content $(p<0.05)$, because it might induce chemical reaction of polyphenol. However, the extracted polyphenols were mainly oligomer and monomers in organic phase that were resistant to temperature, therefore temperature had minor effects on the ferric reducing antioxidant power of organic phase extracts. except for $70^{\circ} \mathrm{C}$. Miguel et al. (2010) found a negative correlation between phenols, flavones and flavonols and antioxidant activity in Portuguese propolis extracts.

At different $\mathrm{pH}$, significant negative correlations between aqueous phase polyphenol content and its corresponding $\mathrm{EC}_{50}$, $\mathrm{EC}_{1}(p<0.01)$ were shown in Table 1. Positive correlations between organic phase polyphenol content and its corresponding $\mathrm{EC}_{50}$ were also demonstrated in Table $1(p<0.01)$. On the contrary, there was no significantly negative correlation with its corresponding $\mathrm{EC}_{1}(p<0.05)$. The results indicated that there was no uniform regularity in the influence of $\mathrm{pH}$ on the change of DPPH radical scavenging capacity, ferric reducing antioxidant power and polyphenol content, which can cause the different effects on specific polyphenol stability.
In terms of light, navel orange peel polyphenol content in aqueous and organic phases and its corresponding $\mathrm{EC}_{50}$ showed a negative correlation $(p<0.01)$. Moreover, a significant positive correlation was also obtained with its corresponding $\mathrm{EC}_{1}(p<$ 0.01 ). These results suggested that the effect of light on navel orange peel polyphenol antioxidant activity was mainly due to polyphenol content under different light conditions. Lin \& Yang (2019) have reported that the illumination was not conducive to polyphenols stability and the condition of avoiding light can protect the polyphenols stability. Therefore, it is necessary to avoid direct light during the storage and application of navel orange peel polyphenols.

Thaipong et al. (2006) reported high positive correlations between polyphenols and FRAP in guava fruit juices. Gardner et al. (2000) have demonstrated the similar behavior in certain pure fruit juices, such as orange, pineapple, apple and grapefruit.

\section{Conclusion}

The kinetic behavior of antioxidant activity of aqueous/ organic polyphenol extracts from navel orange peel were evaluated by using DPPH and FRAP assays. The effects of various factors (temperature, $\mathrm{pH}$, light) on polyphenol content and its antioxidant activity were investigated. The kinetic reaction of polyphenol extracts on DPPH radical scavenging capacity and ferric reducing antioxidant power in aqueous and organic phases was characterized by the dual dependence between concentration and reaction time. The absorption value decreased rapidly in the first $10 \mathrm{~min}$, and $50 \mathrm{~min}$ was required to reach a plateau. The kinetic approach may give a more comprehensive understanding about the behavior of antioxidants. The stability of aqueous and organic phases polyphenol was influenced by temperature, $\mathrm{pH}$ and light. Polyphenol content and its antioxidant activity in aqueous and organic phases from navel orange peel were negatively affected by temperature change from $30^{\circ} \mathrm{C} \sim 70^{\circ} \mathrm{C}$. Aqueous polyphenol content was stable under the condition of pH 3.0 5.0. However, in organic phase, it was stable under the acidic and alkaline conditions. Polyphenol content and its antioxidant activity was gradually decreased when light time increased from $12 \mathrm{~h} \sim$ $96 \mathrm{~h}$. There is a significant correlation between total phenolic content and antioxidant activity. These results would provide comprehensive information on the total antioxidant capacity and influence factors of polyphenol. 


\section{Ethical approval}

This article does not contain any studies with human or animal subjects.

\section{Conflict of interest}

The authors have no conflict of interest to declare.

\section{Acknowledgements}

The authors appreciate the financial support from Guangdong Provincial Key Research and Development Program of China (No. 2020B020226010), Lingnan Bake Food Key Technology and Industrialization Demonstration of New Functional Ingredients (No. 2020B020226010), and Guangdong Provincial Key Laboratory of Lingnan Specialty Food Science and Technology (No. 2021B1212040013); Guangdong Graduate Innovation and Entrepreneurship Training Program (No. 2017QTLXXM24) were greatly appreciated.

\section{References}

Ajila, C. M., Naidu, K., Bhat, S., \& Rao, U. (2007). Bioactive compounds and antioxidant potential of mango peel extract. Food Chemistry, 105(3), 982-988. http://dx.doi.org/10.1016/j.foodchem.2007.04.052.

Akowuah, G. A., Mariam, A., \& Chin, J. H. (2009). The effect of extraction temperature on total phenols and antioxidant activity of Gynura procumbens leaf. Pharmacognosy Magazine, 5(17), 81-85.

Bagetti, M., Facco, E. M. P., Piccolo, J., Hirsch, G. E., Rodriguez-Amaya, D., Kobori, C. N., Vizzotto, M., \& Emanuelli, T. (2011). Physicochemical characterization and antioxidant capacity of pitanga fruits (Eugenia uniflora L.). Food Science and Technology, 31(1), 147-154. http:// dx.doi.org/10.1590/S0101-20612011000100021.

Benzie, I. F., \& Strain, J. J. (1996). The ferric reducing ability of plasma (FRAP) as a measure of "antioxidant power": the FRAP assay. Analytical Biochemistry, 239(1), 70-76. http://dx.doi.org/10.1006/ abio.1996.0292. PMid:8660627.

Bobo-García, G., Davidov-Pardo, G., Arroqui, C., Vírseda, P., Marín-Arroyo, M. R., \& Navarro, M., (2015). Intra-laboratory validation of microplate methods for total phenolic content and antioxidant activity on polyphenolic extracts, and comparison with conventional spectrophotometric methods. Journal of the Science of Food and Agriculture, 95(1), 204-209. http:// dx.doi.org/10.1002/jsfa.6706. PMid:24756821.

Braicu, C., Ladomery, M. R., Chedea, V. S., Irimie, A., \& Berindan-Neagoe, I. (2013). The relationship between the structure and biological actions of green tea catechins. Food Chemistry, 141(3), 3282-3289. http://dx.doi.org/10.1016/j.foodchem.2013.05.122. PMid:23871088.

Calliste, C., Trouillas, P., Allais, D., \& Duroux, J. (2005). Castanea sativa Mill. leaves as new sources of natural antioxidant: an electronic spin resonance study. Journal of Agricultural and Food Chemistry, 53(2), 282-288. http://dx.doi.org/10.1021/jf049341c. PMid:15656662.

Dai, J., Patel, J. D., \& Mumper, R. J. (2007). Characterization of blackberry extract and its antiproliferative and anti-inflammatory properties. Journal of Medicinal Food, 10(2), 258-265. http://dx.doi.org/10.1089/ jmf.2006.238. PMid:17651061.

Do, Q. D., Angkawijaya, A. E., Tran-Nguyen, P. L., Huynh, L. H., Soetaredjo, F. E., Ismadji, S., \& Ju, Y. H. (2014). Effect of extraction solvent on total phenol content, total flavonoid content, and antioxidant activity of Limnophila aromatica. Yao Wu Shi Pin Fen $X i, 22(3), 296-302$. PMid:28911418.
DuPont, M., Bennett, R. N., Mellon, F. A., \& Williamson, G. (2002). Polyphenols from alcoholic apple cider are absorbed, metabolized and excreted by humans. The Journal of Nutrition, 132(2), 172-175. http://dx.doi.org/10.1093/jn/132.2.172. PMid:11823574.

Friedman, M., \& Jürgens, H. S. (2000). Effect of pH on the stability of plant phenolic compounds. Journal of Agricultural and Food Chemistry, 48(6), 2101-2110. http://dx.doi.org/10.1021/jf990489j. PMid:10888506.

Ganapathi, M. R., Naumov, S., Hermann, R., \& Brede, O. (2001). Nucleophilic effects on the deprotonation of phenol radical cations. Chemical Physics Letters, 337(4-6), 335-340. http://dx.doi.org/10.1016/ S0009-2614(01)00216-0.

Gardner, P. T., White, T. A. C., McPhail, D. B., \& Duthie, G. G. (2000). The relative contributions of vitamin $\mathrm{C}$, carotenoids and phenolics to the antioxidant potential of fruit juices. Food Chemistry, 68(4), 471-474. http://dx.doi.org/10.1016/S0308-8146(99)00225-3.

Gliszczyńska-Świgł, A. (2006). Antioxidant activity of water-soluble vitamins in the TEAC (trolox equivalent antioxidant capacity) and the FRAP (ferric reducing antioxidant power) assays. Food Chemistry, 96(1), 131-136. http://dx.doi.org/10.1016/j.foodchem.2005.02.018.

Guo, X., Han, D., Xi, H., Rao, L., Liao, X., Hu, X., \& Wu, J. (2012). Extraction of pectin from navel orange peel assisted by ultra-high pressure, microwave or traditional heating: a comparison. Carbohydrate Polymers, 88(2), 441-448. http://dx.doi.org/10.1016/j.carbpol.2011.12.026.

Hano, C. (2020). Antioxidant and anti-aging action of plant polyphenols. Medicines: MDPI.

Harbourne, N., Jacquier, J. C., \& O’Riordan, D. (2009). Optimisation of the aqueous extraction conditions of phenols from meadowsweet (Filipendula ulmaria L.) for incorporation into beverages. Food Chemistry, 116(3), 722-727. http://dx.doi.org/10.1016/j.foodchem.2009.03.017.

Hertog, M. G. L., Feskens, E. J. M., Kromhout, D., Hertog, M. G. L., Hollman, P. C. H., Hertog, M. G. L., \& Katan, M. B. (1993). Dietary antioxidant flavonoids and risk of coronary heart disease: the Zutphen Elderly Study. Lancet, 342(8878), 1007-1011. http://dx.doi. org/10.1016/0140-6736(93)92876-U. PMid:8105262.

Hou, H., Bonku, E. M., Zhai, R., Zeng, R., Hou, Y. L., Yang, Z. H., \& Quan, C. (2019). Extraction of essential oil from Citrus reticulate Blanco peel and its antibacterial activity against Cutibacterium acnes (formerly Propionibacterium acnes). Heliyon, 5(12), e02947. http://dx.doi.org/10.1016/j.heliyon.2019.e02947. PMid:31872120.

Klangpetch, W., Phromsurin, K., Hannarong, K., Wichaphon, J., \& Rungchang, S. (2016). Antibacterial and antioxidant effects of tropical citrus peel extracts to improve the shelf life of raw chicken drumettes. International Food Research Journal, 23(2), 700-707.

Lin, G. R., \& Yang, L. H. (2019). Study on the effect of processing conditions on the stability of grape polyphenols. Food Science and Technology, 44(11), 267-272.

Lu, Y., \& Foo, L. Y. (2000). Antioxidant and radical scavenging activities of polyphenols from apple pomace. Food Chemistry, 68(1), 81-85. http://dx.doi.org/10.1016/S0308-8146(99)00167-3.

Lux, P. E., Carle, R., Zacarías, L., Rodrigo, M. J., Schweiggert, R. M., \& Steingass, C. B. (2019). Genuine carotenoid profiles in sweet orange [Citrus sinensis (L.) Osbeck cv. Navel] peel and pulp at different maturity stages. Journal of Agricultural and Food Chemistry, 67(47), 1316413175. http://dx.doi.org/10.1021/acs.jafc.9b06098. PMid:31665598.

Magalhães, L. M., Barreiros, L., Maia, M. A., Reis, S., \& Segundo, M. A. (2012). Rapid assessment of endpoint antioxidant capacity of red wines through microchemical methods using a kinetic matching approach. Talanta, 97, 473-483. http://dx.doi.org/10.1016/j. talanta.2012.05.002. PMid:22841111. 
Mandalari, G., Bennett, R. N., Bisignano, G., Trombetta, D., Saija, A., Faulds, C. B., Gasson, M. J., \& Narbad, A. (2007). Antimicrobial activity of flavonoids extracted from bergamot (Citrus bergamia Risso) peel, a byproduct of the essential oil industry. Journal of Applied Microbiology, 103(6), 2056-2064. http://dx.doi.org/10.1111/j.13652672.2007.03456.x. PMid:18045389.

McDonald, S., Prenzler, P. D., Antolovich, M., \& Robards, K. (2001). Phenolic content and antioxidant activity of olive extracts. Food Chemistry, 73(1), 73-84. http://dx.doi.org/10.1016/S0308-8146(00)00288-0.

Miguel, M. G., Nunes, S., Dandlen, S. A., Cavaco, A. M., \& Antunes, M. D. (2010). Phenols and antioxidant activity of hydro-alcoholic extracts of propolis from Algarve, South of Portugal. Food and Chemical Toxicology, 48(12), 3418-3423. http://dx.doi.org/10.1016/j. fct.2010.09.014. PMid:20849908.

Nicolle, C., Cardinault, N., Gueux, E., Jaffrelo, L., Rock, E., Mazur, A., Amouroux, P., \& Rémésy, C. (2004). Health effect of vegetablebased diet: lettuce consumption improves cholesterol metabolism and antioxidant status in the rat. Clinical Nutrition, 23(4), 605-614. http://dx.doi.org/10.1016/j.clnu.2003.10.009. PMid:15297097.

Rafiq, S., Kaul, R., Sofi, S. A., Bashir, N., Nazir, F., \& Nayik, G. A. (2018). Citrus peel as a source of functional ingredient: a review. Journal of the Saudi Society of Agricultural Sciences, 17(4), 351-358. http:// dx.doi.org/10.1016/j.jssas.2016.07.006.

Reyes, L. F., \& Cisneros-Zevallos, L. (2007). Degradation kinetics and colour of anthocyanins in aqueous extracts of purple-and red-flesh potatoes (Solanum tuberosum L.). Food Chemistry, 100(3), 885-894. http://dx.doi.org/10.1016/j.foodchem.2005.11.002.

Rezzadori, K., Benedetti, S., \& Amante, E. R. (2012). Proposals for the residue recovery: orange waste as raw material for new products. Food and Bioproducts Processing, 90(4), 606-614. http://dx.doi. org/10.1016/j.fbp.2012.06.002.

Ruenroengklin, N., Zhong, J., Duan, X., Yang, B., Li, J., \& Jiang, Y. (2008). Effects of various temperatures and $\mathrm{pH}$ values on the extraction yield of phenolics from litchi fruit pericarp tissue and the antioxidant activity of the extracted anthocyanins. International Journal of Molecular Sciences, 9(7), 1333-1341. http://dx.doi.org/10.3390/ ijms9071333. PMid:19325806.

Santos, M. L., López, J. A., Pérez, A. F., \& Martín, A. M. (2010). Modelling the anaerobic digestion of wastewater derived from the pressing of orange peel produced in orange juice manufacturing. Bioresource Technology, 101(11), 3909-3916. http://dx.doi.org/10.1016/j. biortech.2009.12.146. PMid:20137913.

Satari, B., \& Karimi, K. (2018). Citrus processing wastes: environmental impacts, recent advances, and future perspectives in total valorization. Resources, Conservation and Recycling, 129, 153-167. http://dx.doi. org/10.1016/j.resconrec.2017.10.032.

Serafini, M., Bugianesi, R., Salucci, M., Azzini, E., Raguzzini, A., \& Maiani, G. (2002). Effect of acute ingestion of fresh and stored lettuce (Lactuca sativa) on plasma total antioxidant capacity and antioxidant levels in human subjects. British Journal of Nutrition, 88(6), 615-623. http://dx.doi.org/10.1079/BJN2002722. PMid:12493083.

Shirisha, G., Mandava, K., Batchu, U. R., Thammana, K. R., \& Turpu, V. L. (2019). Antitumor and antioxidant effects of flavonoid fraction of Citrus sinensis peel extract. Pharmacognosy Journal, 11(1), 57-63. http://dx.doi.org/10.5530/pj.2019.1.11.

Singh, B., Singh, J. P., Kaur, A., \& Singh, N. (2018). Insights into the phenolic compounds present in jambolan (Syzygium cumini) along with their health-promoting effects. International Journal of Food Science \& Technology, 53(11), 2431-2447. http://dx.doi.org/10.1111/ijfs.13841.

Smeriglio, A., Cornara, L., Denaro, M., Barreca, D., Burlando, B., Xiao, J., \& Trombetta, D. (2019). Antioxidant and cytoprotective activities of an ancient Mediterranean citrus (Citrus lumia Risso) albedo extract: microscopic observations and polyphenol characterization. Food Chemistry, 279, 347-355. http://dx.doi.org/10.1016/j. foodchem.2018.11.138. PMid:30611500.

Suja, K. P., Jayalekshmy, A., \& Arumughan, C. (2004). Free radical scavenging behavior of antioxidant compounds of sesame (Sesamum indicum L.) in DPPH' system. Journal of Agricultural and Food Chemistry, 52(4), 912-915. http://dx.doi.org/10.1021/jf0303621. PMid:14969550.

Szeto, Y. T., Kwok, T. C. Y., \& DPhil, I. F. B. (2004). Effects of a long-term vegetarian diet on biomarkers of antioxidant status and cardiovascular disease risk. Nutrition, 20(10), 863-866. http://dx.doi.org/10.1016/j. nut.2004.06.006. PMid:15474873.

Tabart, J., Kevers, C., Pincemail, J., Defraigne, J., \& Dommes, J. (2009). Comparative antioxidant capacities of phenolic compounds measured by various tests. Food Chemistry, 113(4), 1226-1233. http://dx.doi. org/10.1016/j.foodchem.2008.08.013.

Terpinc, P., Bezjak, M., \& Abramovič, H. (2009). A kinetic model for evaluation of the antioxidant activity of several rosemary extracts. Food Chemistry, 115(2), 740-744. http://dx.doi.org/10.1016/j.foodchem.2008.12.033.

Thaipong, K., Boonprakob, U., Crosby, K., Cisneros-Zevallos, L., \& Byrne, D. H. (2006). Comparison of ABTS, DPPH, FRAP, and ORAC assays for estimating antioxidant activity from guava fruit extracts. Journal of Food Composition and Analysis, 19(6-7), 669-675. http:// dx.doi.org/10.1016/j.jfca.2006.01.003.

Tohma, H. S., \& Gulçin, I. (2010). Antioxidant and radical scavenging activity of aerial parts and roots of Turkish liquorice (Glycyrrhiza glabra L.). International Journal of Food Properties, 13(4), 657-671. http://dx.doi.org/10.1080/10942911003773916.

Wang, S. Y., \& Lin, H. S. (2000). Antioxidant activity in fruits and leaves of blackberry, raspberry, and strawberry varies with cultivar and developmental stage. Journal of Agricultural and Food Chemistry, 48(2), 140-146. http://dx.doi.org/10.1021/jf9908345. PMid:10691606.

Williams, R. J., \& Spencer, J. P. E. (2012). Flavonoids, cognition, and dementia: actions, mechanisms, and potential therapeutic utility for Alzheimer disease. Free Radical Biology \& Medicine, 52(1), 35-45. http:// dx.doi.org/10.1016/j.freeradbiomed.2011.09.010. PMid:21982844.

Yan, Q., Hua, W. F., Dong, W. B., Ting, X. T., \& Peng, S. (2012). Optimization of polyphenol extraction from navel orange peel by response surface methodology. Science and Technology of Food Industry, 33(20), 231-236.

Yang, J., Zhang, G., Wang, J., \& Feng, L. (2009). Response surface methodology as an approach to optimizing ultrasonic-assisted extraction of flavonoids from navel orange peel. Shipin Kexue, 30(16), 94-97.

Yin, B. L., Jing, L., Yuan, Y. D., Juan, Y., Xin, L. P., Gang, Z. (2015). Effects of light on polyphenols and antioxidant activities of Tartary buckwheat buds. Journal of Chengdu University, 34(3), 209-213.

Yoshida, Y., Kiso, M., \& Goto, T. (1999). Efficiency of the extraction of catechins from green tea. Food Chemistry, 67(4), 429-433. http:// dx.doi.org/10.1016/S0308-8146(99)00148-X.

Yuan, X. Y. (2014). Effect of pH and illumination on stability of apple polyphenol. Modern Agricultural Science and Technology, 19, 297-299.

Zaveri, N. T. (2006). Green tea and its polyphenolic catechins: medicinal uses in cancer and noncancer applications. Life Sciences, 78(18), 20732080. http://dx.doi.org/10.1016/j.lfs.2005.12.006. PMid:16445946.

Zhang, H., \& Tsao, R. (2016). Dietary polyphenols, oxidative stress and antioxidant and anti-inflammatory effects. Current Opinion in Food Science, 8, 33-42. http://dx.doi.org/10.1016/j.cofs.2016.02.002.

Zhang, J., Yang, Z., Liang, Y., Zhang, L., Ling, W., Guo, C., Liang, G., Luo, G., Ye, Q., \& Zhong, B. (2018). Effects of postharvest time, heat treatment, $\mathrm{pH}$ and filtration on the limonin content in Newhall navel orange (Citrus sinensis Osbeck cv. Newhall) juice. Molecules, 23(10), 2691. http://dx.doi.org/10.3390/molecules23102691. 